\title{
DESAFÍOS HERMENÉUTICOS: AD INTRA/ AD EXTRA SENTIDO
}

\section{HERMENEUTICS CHALLENGES: AD INTRA/ AD EXTRA MEANING}

\section{RESUMO}

0 artigo trata da diferença entre a interpretação ad extra e ad intra das preposições normativas. Enquanto a interpretação ad intra possui sentido estrito, ligada à teoria da interpretação jurídica de Hans Kelsen, a utilização do sentido ad extra possibilita a solução do problema das chamadas "lacunas da lei", pois a interpretação não se limita à linearidade estrita da palavra, vinculando as normas ao caso concreto. 0 pensamento jurídico moderno se apoiou na Teoria positivista do Direito. Hoje, ela se encontra em ruínas e incompatível com a nova sociedade e os novos direitos e, para adaptar o sistema jurídico aos novos contextos e conflitos atuais, é necessário utilizar a interpretação hermenêutica para ampliar o sentido das normas. 0 trabalho visa mostrar que o verdadeiro espírito das normas possui uma superioridade em relação a tudo o que é puramente ciência, puramente técnico, puramente palavra.

Palavras-chave: Hermenêutica. Interpretação jurísica. Ad extra. Ad intra.

\begin{abstract}
The article deals with the difference between the interpretation ad intra and ad extra of the normative prepositions. While the ad intra interpretation has strict sense, linked to the Theory of legal interpretation of Hans Kelsen, the use of ad extra meaning allows the solution of the problem of the called "gaps in the law", because this interpretation is not limited to the strict linearity of the Word, by linking the norms to the specific case. The modern legal thought held in positivist Theory of law. Today, it's in ruins and is incompatible with the new society and the new rights and, to adapt the legal system to new contexts and current conflicts, it is necessary to use the hermeneutic interpretation to enlarge the meaning of the rules. The work aims to show the true spirit of the rules has a superiority about everything that is purely science, purely technical, purely word.
\end{abstract}

Keywords: Hermeneutics. Legal interpretation. Ad extra. Ad intra.

\section{SUMÁRIO}

1 EPIFANÍAS DEL SENTIDO; 2 LA PROCESIONARIA DEL SENTIDO; 3 QUITAR SENTIDO: SENTIDO AD EXTRA, O SENTIDO-'OTRO'; 4 GRADO CERO DE LA JURIDICIDAD; 5 GRADO AD EXTRA SENTIDO; INSCRIPCIONES; REFERÊNCIAS. 


\section{EPIFANÍAS DEL SENTIDO}

El penúltimo de los aforismos tractarianos (Tractatus Lógico-Philossophicus, 1918) reza:

Mis proposiciones son esclarecedoras de este modo; que quien me comprende acaba por reconocer que carecen de sentido, siempre que el que comprenda haya salido a través de ellas fuera de ellas. (Debe, pues, por así decirlo, tirar la escalera después de haber subido.) | Debe superar estas proposiciones; entonces tiene la justa visión del mundo. (af: 6.54)

Se formula en él una proposición de tipo pre-apofántica, pre-enunciativa; una proposición, en suma, pre-objetivable. Wittgenstein nos trae a presencia el límite y desde allí la contemplación del ad extra de sentido, el hacia fuera, las tinieblas exteriores.

De la otra parte -el hacia dentro, ad intra del sentido- las proposiciones son menos atrevidas y de naturaleza bien distinta. Muy diferentes y ciertamente cautelosas remiten, todo lo más, como así sucede en la teoría de la interpretación jurídica de Kelsen, al problema de las lagunas de la ley, cuya índole es sin embargo propiamente una falacia. ${ }^{1}$

Y lo es, primero y principal, por sostener que aun cuando pareciera corresponder a la interpretación un papel especial en la tarea de llenar las lagunas de la ley, no hay, empero, auténticas lagunas [...] La llamada laguna no es por ende otra cosa que la diferencia entre el Derecho positivo y un orden mejor, mas justo y más recto.

Los dilemas que de cualquiera deficiencia comparativa pudieran originarse no se resuelven por vía interpretativa ya que la posible respuesta trasciende a la norma positiva, va más lejos, y consiste en "eliminarla para reemplazarla". No se activa allí, por tanto, un procedimiento interpretativo, sino creativo, ultra legem, donde "la norma original es suprimida de golpe y sustituida por otra nueva". Pero en tales casos, escasos y muy concretos, el legislador kelseniano no actúa como el proponente tractiano; no tira la escalera después de haber subido: en realidad, sólo aparenta apoyarla sobre otro muro. Éste otro muro habría de ser uno exterior, ad extra del sentido del Derecho positivo.

Ahora bien, Kelsen elude el desafío y no alonga en el afuera. Tras la sacudida, la prescindencia y la suplantación, habla sólo y exclusivamente de ficción, que aquí es también un

${ }^{1}$ KELSEN, Hans. La Teoría Pura del Derecho: Introducción a la Problemática Científica del Derecho, con pról. de C. Cossio, Editora Nacional México: Editora Nacional, 1981, p. 138-140. 
recurso ad intra del sentido. Nada nos deja ver cuya relevación difiera hacia el exterior. Y es porque, para Kelsen, a fuer de o como consecuencia de la "apariencia” de un complemento del orden jurídico, continúa existiendo únicamente puro interior de sentido, aun cuando se trate de un sentido diferente del 'original', sea incluso como sentido modificado de contrario. Con Kelsen se está, en efecto, a salvo de exposiciones al vértigo del “derecho deseado".

Las llamadas 'lagunas técnicas’ plantearían una perplejidad, vacilación, no obstante, pronto superada. Allí también la Teoría Pura del Derecho construye respecto de otra posible revelación del sentido un antepecho en el que el orden jurídico válido se afirma como valor de verdad, dejando espacio suficiente, margen seguro, con el borde del sentido. Apofántico, enunciativo y objetivable, sin reserva de condiciones, el sentido llega hasta donde su límite, el sentido es allí su límite: hay siempre un límite al sentido, visible como una herida cerrada, como cicatriz del derecho deseado.

Y si todavía Kelsen admite la eventualidad de que una norma prescriba algo sin sentido, algo desprovisto de sentido, lo que no puede ser absolutamente excluido, dado que es "obra humana”, pero en ese caso "ninguna interpretación está capacitada para adjudicarle un sentido; pues por medio de la interpretación no puede arrancarse a una norma lo que no esta antes contenido en ella". ${ }^{2}$

No existe, pues, sentido excedente, porque el sentido está y es, incluso si como -como si- una figuración de sentido, o no, y entonces no es, no está, ni se le puede figurar. No cabe colmatar el ad extra del sentido; el vacío es irrellenable. Lo desocupado de sentido, el afuera, es un indescriptible, inconfigurable, del que no es posible argumentar o interrogarse. Y, así, indecible, inefable, silente. En llegando a ese punto, la extenuación del sentido, su acabamiento, al ras mismo de límite, de la intermisión de sentido, e instante antes de traspasarlo, se retorna también al finalísimo Wittgenstein:"De lo que no se puede hablar hay que callar" (af: 7).

Solo que en Kelsen opera como mecanismo de feed back, autopoiético, de control regulatorio del sentido en reverso, en tanto que el ofrecimiento wittgensteiniano era promesa y desafío de afrontamiento -to enter- hacia lo carente de sentido. Llegando a la demarcación última la teoría de la interpretación jurídica kelseniana -y toda aquella que hasta ayer la heredó, vasta genealogía del positivismo- enuncia sólo una pregunta, única, de respuesta gnoseológicamente perentoria: cómo volver al adentro, no cómo ingresar al afuera.

${ }^{2}$ KELSEN, Hans. La Teoría Pura del Derecho: Introducción a la Problemática Científica del Derecho, con pról. de C. Cossio, Editora Nacional México: Editora Nacional, 1981, p. 142-143. 


\section{(1)

\section{LA PROCESIONARIA DEL SENTIDO}

Una primera imagen me socorre en la idea del sentido. La de sentido peregrino, sentido que viene de lejos, y también de peregrinaje del sentido, sentido ambulante en escala y transito por estaciones de sentido. De esa peregrinación excluyo sin embargo alcanzar un destino, algún tabernáculo santo, altar del sentido, pero entonces su itinerario sería sólo vagar, únicamente errancia y digresividad. Desisto de ella y busco otra imagen.

La Zoológica me presta una entre sus muchos catálogos atroces. El sentido camina como un ciempiés, un miriádopo, un insecto de cuerpo segmentado en anillos articulados, provisto de uno o dos pares de patas por cada de ellos, capaz así de avanzar o retroceder según precise, de movimiento muy veloz, a veces con súbitos detenimientos, que luego reemprende y prosigue y otra vez se contiene, y en esa repetición de avance, espera y reinicio advierto su desplazamiento (trayectos) y percibo las distancias (tramos) recorridas. Pierdo en esa carrera, sin embargo, la continuidad, el continuum del sentido. Me distrae, además, su unidad elemental. Dimito también de ella.

Pergeño y dispongo otra más. Sentido como organismo complejo y móvil, una colonia en movimiento, cuya sucesiva diligencia es el despliegue sobre sí misma de en adelante a sí misma Intuyo ahí a la procesonaria del sentido. Así, el sentido como una oruga -el insecto lepidópterio que estraga el pino o el cedro- adherida a otra, alineada con la inmediata anterior y precediendo a la siguiente, que marcha en cadeneta; el sentido forma hilera, el sentido es el desfile, el sentido deviene discurso.

El sentido es discurso, no un ser o un estar; el sentido es la procesión del sentido. No un es recóndito, enclavado, o un está subrepticio u oculto, éste hermetizado en un juego -raro juego- del esconder, disimulo que al fin aflora, aquél como secreto extirpado de lo más intestino y que a la postre queda al descubierto.

El sentido es su lógica procesional. Conferir sentido 'no es' enderezarlo a un principio, 'no está' en gobernarlo a un finito, a un lugar definitivo. Sobre la lógica del 


\section{政

José CALVOGONZÁLEZ

sentido escribe Deleuze: "el sentido no es nunca principio ni origen, es producto. No está por descubrir, ni restaurar ni reemplazar; está por producir con nuevas maquinarias". ${ }^{3}$

Entonces, concluyo de ahí, sentido es el resultado de la construcción de la acción prosecutiva, proseguida, es la serie del sentido. Dar sentido es, en realidad, moverse a lo largo del sentido. Otorgar sentido no consiste en retroceder hasta un depósito ab origine, motor inmóvil del sentido, ni tampoco remontar hacia un sentido ulterior, morada y residencia más exaltada del sentido. Dar y otorgar sentido radica en continuar y seguir el hilo de sentido, en desarrollar y extender la línea de sentido. Algo recibe sentido porque -ahora, no antes, ni después- está en el sentido, porque es en el sentido.

De ese modo, la dación u otorgamiento de sentido a través de la interpretación teórica o práctica de una norma jurídica acontecería, a mi juicio, no por efecto del rescate de un contenido estanco que sea o esté a lo primero o a lo último, sino del despliegue o dilatación del sentido. De ello es ejemplo sobresaliente el proceso hermenéutico constitucional que da y otorga sentido a la interpretación tendente a maximizar y optimizar la fuerza expansiva y la eficacia de los derechos fundamentales en su conjunto. 0 lo que es igual, en esa idea regulativa de optimización de la garantía institucional y de privilegiar máximamente la protección y ejercicio de cada derecho fundamental, la labor interpretativa ha diseñado una nueva maquinaria de dación u otorgamiento de sentido que no era ni estaba, que no preexistia ni sobrevenía: la ponderación principalista. Máquinas de sentido tales como: principio de interpretación evolutiva, principio de interpretación conforme, principio de interpretación extensiva de los derechos y restrictiva de sus limitaciones, principio interpretativo de útil efectividad, principio interpretativo de progresividad, de irreversibilidad, de interacción, de indivisibilidad ... Todos ellas evidencian -al margen de cualquier polémica posible- algo común: que el método de extracción de sentido jurídico utilizado en la

${ }^{3}$ DELEUZE, Gilles. Lógica del sentido, trad. de Víctor Molina y Miguel Morey, pról. de Miguel Morey, Barcelona; Buenos Aires; México: Paidós, 1989, p. 90 
interpretación constitucional por la máquina hermenéutica clásica ${ }^{4}$ no representaba mejor aún, tampoco representaba- una adecuada recuperación de sentido, sea porque ciertamente no bastara para producirlo con 'arrancarlo' de norma, sea porque al no existir ésta tampoco aquello resultaba posible.

Pero, diré asimismo, que la imagen de la línea de sentido no se comprime a la linealidad de sentido. La línea de sentido puede abrirse a diferentes formas, puede formar redes de sentido, puede también disponerse en trazo curvilíneo.

Reticulada, en rizoma, la línea de sentido soslaya que la prescripción de una norma pueda estar evadida del sentido o ser un sinsentido, algo desprovisto de sentido, porque tal presunta huída o carestía de sentido se predica en realidad respecto del conjunto de sentido jurídico -esto es, la coherencia y eficacia del sistema u orden jurídico ${ }^{5}$; por él precisamente aquella norma presenta ese absurdo de sentido, ese sentido ad absurdum. Su sinsentido como absurdo es, por tanto, una absurdidad llena de sentido. A tal sentido no obtenido se llega interpretativamente haciendo funcionar la máquina de sentido constructivo 'sistema' u 'ordenamiento', en la que argumentalmente la reductio ad absurdum actúa como uno de sus mecanismos de producción de sentido.

Por lo demás, ésta me parece más la respuesta a que pueda existir una norma sin sentido, carente de sentido, absurda, que responderla por su inconsistencia con la racionalidad del legislador, ${ }^{6}$ pura ideología postulada en la(s) mitología(s) de la razón

\footnotetext{
${ }^{4}$ V. gr.: derechos fundamentales interpretados con sentido de garantía de la autonomía individual, de categorías jurídico-formales arregladas a la metodología interpretativa tradicional de una ley y, por último, como categorías independientes. Véase por mentor FORSTHOFF, Ernst. Rechtsstaat im Wandel, Verfassungrechtliche Anhandlungen. Stuttgart: W. Kohlhammer Verlag, 1964, p. 131, y los comentarios y análisis de BOCKENFORDE, Ernst. Escritos sobre derechos fundamentales, trad.de Juan Luis Requejo Pagés e Ignacio Villaverde Menéndez, Baden-Baden: Nomos Verlarsgesellchaft, 1993, p. 15-19.

5 Véanse: EZQUIAGA GANUZAS, Francisco Javier. La argumentación en la justicia constitucional española. Oñati: Instituto Vasco de Administración Pública, 1987, p. 247 y ss ISONOMÍA. Argumentos interpretativos y postulado del legislador racional. Revista de Teoría y Filosofía del derecho, ed. 1, 1994, p. 69-98, así como GUASTINI, Ricardo. Estudios sobre la interpretación jurídica, trad. de Marina Gascón y Miguel Carbonell, México: Instituto de Investigaciones Jurídicas, Editorial Porrúa/UNAM, 2000, p. 32-33.

${ }^{6}$ Véanse : BOBBIO, Norberto. Le bon législateur. In: BOBBIO, Norberto. Le raisonnement juridique. Bruxelles: Ed. Hubert Hubien, Etablissement Émile Bruylant, 1971, p. 244-249, en esp. p. 245-246, y OST, François, L'interprétation logique et systématique et le postulat de rationalité du législateur.
} 
JosÉ CALVOGONZÁLEZ

pues, de hecho, en términos de tecno-praxis, "siendo la ley obra humana, eso no está excluído"; e igualmente, y más todavía, que aquella otra que la responde como causada por una inconsistencia de la norma en cuestión consigo misma, al menos desde que la teoría compositiva otorga sentido a cualquier combinación de palabras -'sentencia'capaz de enunciar un mensaje inteligible, y, por tanto, algo que a menudo aparentara ser un absurdo debería contarse entre lo que tiene sentido, ${ }^{7}$ junto -por último- también al no menor inconveniente de respuesta que se trae del desacuerdo cultural sobre la propia categoría de absurdo. ${ }^{8}$

Y asimismo cabe que la imagen de la línea de sentido adopte la curva como su forma. En una nueva máquina de sentido jurídico -el Derecho curvo- donde antes la geometría dogmático-formal estancaba a un punto agudo (vértice normativo) el principio u origen de sentido, se describe ahora una abombada cúpula, y donde la clásica planicidad, constituida por una superficie frontal (derecho estatal prima facie) y varias llanuras de sentido (de cada grada o escalón normativo), una revolución. ${ }^{9}$

Del resto, siendo que el sentido se produce en su lógica procesional $\left(S_{0}, S_{1}, S_{2}\right.$,

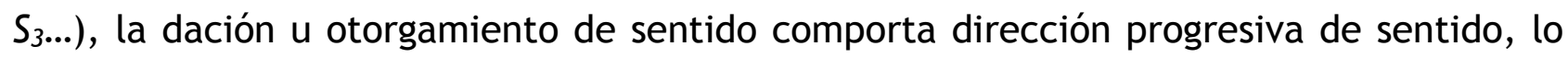
que así la definiría ad intra por añadir de sentido.

\section{QUITAR SENTIDO: SENTIDO AD EXTRA, O SENTIDO-‘OTRO’}

El encadenamiento de la procesionaria del sentido compone la columna de sentido. En la Teoría del derecho ésta hizo de pilastra del logos jurídico. En ella apoyó toda la fábrica del pensamiento iusfilosófico hasta la edad moderna y tardocontemporánea. Sin embargo, los muros del edificio, levantados a contra ángulo esquina iusnaturalista vs. esquina iuspositivista- han colapsado. El cuadrángulo de la

L'interpretation en droit : Approche pluridisciplinaire, Publications des Facultés Universitaires SaintLouis, Bruxelles: Ed. Michel van de Kerchove, 1978, p. 97-184, en esp. p. 139.

${ }^{7}$ Sobre la quimera de que una sentencia invariablemente tenga sentido o carezca de él véase BAKER, Gordon .P. ; HACKER, Peter M.S. Language, sense and nonsense: a critical investigation into modern theories of language. Oxford: Blackwell, 1984, p. 336-338.

${ }^{8}$ TARELLO, Giovanni. L'interpretazione della legge. Milano: Giuffrè, 1989, p. 370.

${ }^{9}$ CALVOGONZALES, José. Direito curvo, trad. de André Karam Trindade, Luis Rosenfield y Dino del Pino, Posfácio de Lenio Luiz Streck, Porto Alegre: Livraria do Advogado, 2013, en esp. p. 32. 
obra, en todos sus lienzos, desplomado, ha caído. Hoy la teoría jurídica habita en un templo derruido, habita sus ruinas, habita su ruina. Pronto quedará a la intemperie del sentido, y estará entonces en el afuera. La tarea es, desde ya, averiguar con qué nuevas maquinarias hermenéuticas desafiaremos el sentido ad extra.

Ahora la única interrogante, de resolución improrrogable, es cómo inquirir sobre del lugar sin nombre. Para ello es seguro que en la interioridad de la reflexión filosófica y la positividad de nuestros saberes habremos de instituir una alternativa gnoseológica. Foucault -premonitorio- la relacionó con lo que llamaba pensée du dehors. ${ }^{10}$ Con la mirada puesta en el marco específico del saber filosófico-jurídico Carcova ha hablado de teorías jurídicas post positivistas. ${ }^{11}$ A partir de esas referencias algunos hemos comenzado a indagar, con recurso a la metodología crítica e instrumentos de conocimiento multi y transdisciplinarios, determinadas zonas aledañas de ese espacio ad extra. En orden a ciertas dimensiones de la hermenéutica socio-jurídica sin duda el lindero se ha cruzado. Con todo, la cuestión acerca de qué modo construir sentido ad extra permanece planteada como un desafío que, en general, se encuentra todavía pendiente de abordajes. Las enormes implicaciones y su problematicidad son poco discutibles, especialmente porque la inédita idea de sentido preliminar requiere intervenir con una mecánica epistemológica cuyo funcionamiento supone la insólita ruptura con el sentido ad intra que ahora queda ya del otro lado.

Que la columna de sentido esté desarticulada nos ha ido llevando al destierro, a la expatriación del sentido. Y allí, en mitad de ninguna parte, si es cierto que contemplamos la desolación del sentido contemplamos también paños de la antigua fachada de sentido que aún se mantienen en pie, melancólico testimonio para la recordación de su otrora pujanza.

$Y$ es que, en efecto, no se ha producido una demolición completa de nuestra estructura conceptual de sentido, y ello mismo condiciona el paso al afuera, al sentidootro. A éste, así, todavía, a menudo lo fascinamos como una simple desviación de la

\footnotetext{
${ }^{10}$ FOUCALT, Michel. La pensée du dehors. Critique, ed. 229, p. 523-546. LÁZARO, Manuel Arranz. EI pensamiento del afuera. Valencia: Pre-textos, 2008.

${ }^{11}$ CARCOVA, Carlos María. Las teorías jurídicas post positivistas. Buenos Aires: Lexis Nexos, 2007 [2 ${ }^{\mathrm{a}}$ ed. en Abeledo Perrot, Buenos Aires, 2009].
} 


\section{政

José CALVoGonzÁLEZ

columna de sentido, quizá como una intermisión, interrupción, cesación, detención, quizá una digresión, un paréntesis, una dilación acaso. Aún no hemos tomado auténtica conciencia -autoconciencia- de la diáspora del sentido.

Desviarse de la columna de sentido, o cualquiera otro de los episodios reseñados, era efecto de sentido no querido, pero producido ad intra sentido e reintegrable -con mayor o menor inconveniente- en la escena jurídico-interpretativa de su representación. No generaba situaciones ab scena. En la elástica de la procesionaria del sentido cabía admitir la producción de equívocos (desacuerdos) de sentido, de ambigüedades (casos difíciles), incluso la vaguedad (conceptos jurídicos indeterminados). En lo más rígido de su lógica procesional tampoco se excluía la aparición de contra-sentidos (antinomias). Todos estos escenarios, sin embargo, eran atribuibles al efecto del movimiento de sentido, a su dinámica; eran esguinces de sentido, o sobrecargas de sentido. Era posible llegar hasta, incluso, la extenuación de sentido (casos trágicos). No por ello, empero, el sistema u orden jurídico se vaciaba de sentido; muy al contrario, su integración añadía sentido, otros sentidos, y aumentaba el abasto de sentido. El almacén de sentido nunca se vaciaba.

El escenario es en este momento tan 'lugar-otro', es ab scena, que llegar a saber dónde y cómo posicionarnos en él parece no anticipar expectativa interpretativa alguna, pero es así porque incumbido por el vacío de sentido la estrategia que precisamente le concierne es sólo aquella en la que se resta sentido, una estrategia de drenaje, de descarga, de desabastecimiento de sentido. Se trata de vaciar el almacén de sentido.

En al menos dos oportunidades Barthes aquilata esta idea de sentido ad extra como quita de sentido, exención de sentido, viudez de sentido. Dice:

[...] "aniquilar" el sentido es un proyecto desesperado, a proporción de su imposibilidad. [...] no hay sino a título de proyecto un "grado cero" del sentido [...] especie de epopeya del sentido, adámica por así decirlo, puesto que es la del primer hombre, anterior al sentido. ${ }^{12}$

\footnotetext{
12 BARTHES, Roland. Literatura y significación. In: BARTHES, Roland. Ensayos críticos, trad. de Carlos Pujol, Barcelona: Seix Barral, 1967, p. 309-330, en esp. p. 321-322.
} 
[...] lo que yo llamo una exención total del sentido. Eso no tiene nada que ver, estructuralmente, con el absurdo; el absurdo o la absurdidad es un sentido, precisamente el sentido del absurdo; la exención del sentido es un estado del sentido infinitamente más difícil de realizar, es una especie de vacío de sentido, o mejor, es el sentido experimentado y leído como vacío, y ese no es el caso del absurdo [...] la idea de un lenguaje vacío, de un sentido vacío (...) una especie de vaciado, de viudez del sentido [...] la empresa más difícil del mundo no es dar sentido (lo hacemos naturalmente), sino, al contrario, quitar sentido. ${ }^{13}$

Las máquinas de achicar sentido que Barthes utiliza en estos dos fragmentos son artefactos degresivos que infiere en textos de Blanchot, siempre oscilantes entre la crítica y la creación literaria. ${ }^{14}$ De ellos colige también Foucault el dehors. ${ }^{15}$ Barthes detecta su actividad como aplazamiento de sentido -no a título de proyectiva, de lo abierto a la provisión de sentido, sino del sentido suspenso, de abertura al vacío de sentido- en tres lenguajes: lenguajes formalizados de las matemáticas o la lógica (“constituidos por puras relaciones, pero en esas relaciones no hay ninguna plenitud de sentido insertada”); lenguajes de las experiencias míticas (y antes en la ascesis del zen que en las descripciones de la mística cristiana) ${ }^{16}$, y lenguajes de cierta vanguardia literaria (los textos y el pensamiento de un grupo como el de la revista Tel Quel).

A mi juicio, este listado de sentido vacío aún consiente ampliaciones de ruptura gramatical de lenguajes: del musical en el método dodecafónico de composición mediante desanclaje con la tonalidad de las piezas para piano y para orquesta en el ciclo de las Op. 11 a Op. 20 de Arnold Schoenberg ${ }^{17}$ y, sobre todo, la mancha muerta en

\footnotetext{
${ }^{13}$ BARTHES, Roland. Una problemática del sentido. (1970). In: BARTHES, Roland. Variaciones sobre la escritura, selec. y trad. de Enrique Folch González, Barcelona: Paidós, 2002, p. 43-63, en esp. p. 51-52. ${ }_{14}^{14}$ BLANCHOT, Maurice. L'espace littéraire, trad. de Vicky Palant y Jorge Jinkis e introd. de Anna Poca, Buenos Aires: Paidós, 1969.

${ }^{15}$ BLANCHOT, Maurice. Aminadab. Paris: Le Très-Haut, Gallimard, 1949.

16 No impugno, pero objeto a pesar de todo. La Noche oscura del alma, de Teresa de Jesús, me parece un ejercicio de exoneración de sentido. Y en las Coplas hechas sobre un éxtasis de alta contemplación, de Juan de la Cruz léese: "Entréme donde no supe:/ y quedéme no sabiendo,/ toda ciencia trascendiendo/ Yo no supe dónde estaba,/pero, cuando allí me vi,/ sin saber dónde me estaba,/ grandes cosas entendí;/ no diré lo que sentí, / que me quedé no sabiendo, / toda ciencia trascendiendo (...)".

${ }^{17}$ SCHOENBERG, Arnold. Fundamentals of Music Composition (1967), trad. de A. Santos, Madrid: Grupo Real Musical, Villaviciosa de Odón, 2000. Véase también PAZ, Juan Carlos, Arnold Schoenberg, o el Fin de la era tonal. Buenos Aires: Editorial Nueva Visión, 1958.

Circunstancias lectura de varios textos de Schoenberg reunidos en El estilo y la idea (trad. de Juan J. Esteve, introd.. de Ramón Barca, Taurus, Madrid, 1963) y la audición de algunas de las composiciones para piano sobre los 15 lieder de Stefan George a que aplicó su método de atonalidad libre en el decurso temporal musical, me transportan hacia una reflexión colateral sobre de armonía y melodía en la Teoría
} 
el lenguaje pictórico de la teoría espiritual del arte de Wassily Kandinsky. Así, donde éste escribe:

Un gran triángulo dividido en partes desiguales -la más pequeña y aguda se encuentra en la cumbre-, representa bastante bien en forma esquemática la vida espiritual. Hacia la base las partes son cada vez más grandes, anchas espaciosas y altas,

Mediante un movimiento apenas sensible el triángulo, en su totalidad avanza y sube lentamente; de ese modo, la parte más próxima al vértice alcanzará 'mañana' el lugar en que la punta estaba 'hoy'.

$[\ldots]$

Este esquema de la vida espiritual sólo ofrece de ella una imagen incompleta. Descuida todo un costado de sombra, un gran sector oscuro, una mancha muerta. Muy a menudo ese pan llega a ser el alimento de cuantos se mantienen en un plano más elevado. Pero existe el peligro de que se convierta para ellos en un veneno. Una pequeña dosis basta para obrar sobre el alma, para hacerla deslizar gradualmente, cada vez más hacia abajo. Si se lo absorbe en una dosis alta, este veneno arrastra al alma a una caída brutal.

[...] Las almas caen sin cesar en los lugares más inferiores del triángulo, el cual, en su conjunto, da la impresión de ser inmóvil, aunque, en realidad, retrocede y desciende. $^{18}$

Aunque las atmósferas de cielo e infierno, que tanto me recuerdan a William Blake, sobrepujan mi interés, no cabe duda que el texto kandinskyano es un testimonio de extraordinaria capacidad alegórica para apreciar la comunicación -pasadizos estéticos- de la escuela vienesa del Derecho con el ambiente espiritual de las vanguardias. Las dimensiones de una transformación epocal, es decir, aquello que en la

del Derecho. Me interrogo acerca de la posibilidad, aun hipotética, de transposición de lo leído y oído al pentagrama del orden musical jurídico. Así, en general, la melodía jurídica sería representable en una sucesión horizontal, junto al ritmo y la cadencia, como combinación evolutiva de la actividad tonal. A diferencia de ella, el principio armonía jurídica, al que correspondería conformar las relaciones internas del sistema jurídico-musical mediante simultaneidad y consonancia de tonos, es una estructura de escalas constructivamente vertical. Entonces, ¿nuestra cultura jurídica es hoy más melódica que armónica, o al revés? Para algunas culturas musicales (música homofónica) lo melódico es más valioso, y hasta fundamental, básico, que la organización de las claves armónicas (música polifónica). ¿Sucede así también en las culturas jurídicas? y, sobre todo, ¿sucede ahora?

Para Schoenberg melodía y armonía poseían igual rango, y así las relaciones entre las notas -tanto verticales como horizontales- permitían que el sonido se produjera por series de variación perenne, ciego al tiempo; es decir, sucesivo y simultáneo.

Cuando planteamos la historia constructiva del orden jurídico, y del kelseniano en particular, raramente introducimos el concepto estético de euritmia, tanto del cifrado musical como del móvil y dinámico en la danza, y obviamos el contexto cultural de las vanguardias históricas donde nuevos avances en la música y el baile, además de la gráfica y la pintura, suscitaban una reflexión sobre proporción, equilibrio, estabilidad y belleza a la que la 'vanguardia jurídica' seguramente no fue insensible.

${ }^{18}$ KANDINSKY, Wasily. De lo espiritual en el arte y la pintura en particular, trad. de Edgar Bayley, Buenos Aires: Galatea Nueva Visión, 1971, p. 18-20. 
JosÉ CALVOGONZÁLEZ

historia del pensamiento, y en este caso al jurídico, hace "avanzar al carro recalcitrante" 19 de la Humanidad, no se encuentran separadas, ni intelectual ni materialmente, ni individual ni colectivamente, de las diversas maneras que en ese momento se experimentaba la innovación y así la configuran y confirman.

\section{GRADO CERO DE LA JURIDICIDAD}

Las aves volvieron al huevo en torbellino de plumas. Los peces cuajaron la hueva, dejando una nevada de escamas en el fondo del estanque. Las palmas doblaron las pencas, desapareciendo en la tierra como abanicos cerrados. Los tallos sorbían sus hojas y el suelo tiraba de todo lo que le perteneciera. El trueno retumbaba en los corredores. Crecían pelos en la gamuza de los guantes. Las mantas de lana se destejían, redondeando el vellón de carneros distantes. Los armarios, los vargueños, las camas, los crucifijos, las mesas, las persianas, salieron volando en la noche, buscando sus antiguas raíces al pie de las selvas.

Todo lo que tuviera clavos se desmoronaba. Un bergantín, anclado no se sabía dónde, llevó presurosamente a Italia los mármoles del piso y de la fuente. Las panoplias, los herrajes, las llaves, las cazuelas de cobre, los bocados de las cuadras, se derretían, engrosando un río de metal que galerías sin techo canalizaban hacia la tierra. Todo se metamorfoseaba, regresando a la condición primera. El barro volvió al barro, dejando un yermo en lugar de la casa. ${ }^{20}$

Cuando el sentido ad intra, invirtiendo la marcha de sentido regresa a la semilla, hasta su núcleo constructivo, creemos que allí está el final del principio. Pero el cuento de Carpentier nos seduce con una falacia. Ni siquiera en él, un ficcional no verosimil, el borrado de sentido traslada al grado cero de sentido, sino a la culminación de sentido que es coincidente con el final de sentido. En ese relato hubo desde el principio un final de sentido; en efecto, al término del relato los obreros encargados en derruir la casa del

\footnotetext{
${ }^{19}$ KANDINSKY, Wasily. De lo espiritual en el arte y la pintura en particular, trad. de Edgar Bayley, Buenos Aires: Galatea Nueva Visión, 1971, p. 18.

${ }^{20}$ CARPENTIER, Alejo. Viaje a la semilla (1944). In: CARPENTIER, Alejo. Guerra del tiempo y otros relatos. Madrid: Alianza Editorial, 1958, p. 9-25, en esp. p. 25.
} 
protagonista de la historia -la tarea de demolición del sentido- comprueban "el trabajo acabado". ${ }^{21}$ Esto es, con la inversión del sentido se alcanza la culminación de sentido. Lo que en realidad acontece en el cuento de Carpentier es que principio y final copulan, son sucesivos, circulares, y el borrado del sentido proporciona sentido al énfasis de sentido.

$\mathrm{Ni}$ por un momento, pues, hemos salido del interior del sentido. Lo que llamamos grado cero del sentido mantiene intacta la legibilidad de sentido ad intra. La linealidad de sentido ad intra comienza en cero. El sentido ad extra lo hace en antes de cero, en menos cero, y para ello se ha de penetrar en el afuera, porque el solo exterior del afuera, el afuera de sí, no supera el sentido boderline.

Es contemplado de este modo que el grado cero de la juridicidad no equivaldría a cero de sentido, sino a la inauguración desde cero de la juridicidad, cuya serie $-S_{1}, S_{2}$, $S_{3 . . .-}$ sucede y se prolonga en adelante. El grado cero y lo en mayor o menor grado numeroso de la ulterior construcción edifican el sentido de la juridicidad. Cuando ésta regresa a cero, ad ovo del sentido, a la simiente, retorna al momento en que el sentido de la juridicidad aún permanecía por producir.

Algunos autores ${ }^{22}$, partiendo del examen de sistemas jurídicos evolucionados -es decir, de una serie ya construida, o al menos en estado de avanzada construcción-, han ensayado aislar el sentido de la juridicidad mediante observación de la paulatina intensificación de la complejidad social del conflicto en cuyo desenvolvimiento institucional van apareciendo la mediación, los tribunales, la policía y los profesionales del Derecho. A partir de aquí, se ha considerado que la composición de tal escala -donde cada nivel es condición necesaria, pero no suficiente para el siguiente- permitiría a su vez clasificar "las sociedades (por su grado de juridicidad), según que no posean ninguna de esas instituciones, que posean algunas de ellas o todas ellas" $y$, asimismo, distinguir "un grado cero de la juridicidad, un grado uno (representado por la mediación) un grado dos (mediación más tribunales), un grado tres (mediación, tribunales y policía), un grado

${ }^{21}$ CARPENTIER, Alejo. Viaje a la semilla (1944). In: CARPENTIER, Alejo. Guerra del tiempo y otros relatos. Madrid: Alianza Editorial, 1958, p.25.

${ }^{22}$ SCWARTS, Richard D.; MILLAR, James C. Legal Evolution and Societal Complexity. American Journal of Society, ed. 70, 2 (set. 1964), p. 159-169. 
cuatro (mediación, tribunales, policía y abogados) un grado cinco (cuando aparece la legislación), etc."23

Creo que este análisis, aunque ofrezca un valioso modelo descriptivo del funcionamiento de la maquinaria de producción de sentido jurídico, no es la única vía de explanar el sentido de la juridicidad. La visión que en ella asimila el recorrido del lus a su Theatrum iuris necesariamente incurre al grado cero de la juridicidad en lo vano, de donde el sentido de la juridicidad devendría ex nihilo.

En mi opinión, constitutivamente -es más, constitucionalmente- el grado cero de la juridicidad se instala desde la Soberanía. Soberanía, pues, como el grado cero del arranque de sentido. La Soberanía no es la juridicidad desnuda de sentido, sino el sentido de la juridicidad al desnudo, el borderline como huella del paso desde afuera a lo social y jurídico instituyente.

Los presupuestos -y también los corolarios- de esa perspectiva de ligamen entre Soberanía y Constitución son políticos ${ }^{24}$ y no eluden pronunciarse sobre obstáculos como la naturaleza y continuidad del poder constituyente ${ }^{25}$ en tanto que máquina de sentido de los derechos.

\section{GRADO AD EXTRA SENTIDO. INSCRIPCIONES}

Del sentido interior del afuera, donde el vacío se espesa hasta lo neutro en silencio estremecedor, únicamente inscripciones, pocas. La principal, una indecible Soberanía. Y si acaso probada a 'nombrar' como Soberanía, Soberanía entonces de sentido-otro con el límite del sentido ad intra, y que le antecede. Soberanía en el sentido del en sí del afuera. Soberanía en gradon ad extra sentido, "grado del exceso de

\footnotetext{
${ }^{23}$ ATIENZA, Manuel. El sentido del Derecho. Barcelona: Editorial Ariel, 2001, p. 29-30.

${ }^{24}$ Véase en CALVOGONZALES, José. De la nostalgia civil: la soberanía popular. In: PALOMBELLA, Gianluigi. Constitución y soberania: El sentido de la democracia constitucional. Granada: Editorial Comares, 2000, p. 13-16, al que asimismo hice traducción.

${ }_{25}$ BATAILLE, Georges. Lo que entiendo por soberanía (1953), trad. de Pilar Sánchez Orozco y Antonio Campillo, introd. de Antonio Campillo, Barcelona: Paidós/I.C.E. de la Universidad Autónoma de Barcelona, 1996: "Soberano es el que es, como si la muerte no fuera. E incluso es el que no muere, pues sólo muere para renacer" (p. 85).
} 
sentido de Soberanía. Soberanía tratada de nombrar a través del Walten heideggeriano: ultra-soberano de la soberanía.

Grado $^{\mathrm{n}}$ de exceso sería, utilizando las palabras de Derrida:

El de una soberanía tan soberana que excede a las figuras o las determinaciones teleológicas y políticas -y sobre todo ontoteológicas- de la soberanía. El Walten sería tan soberano, ultra-soberano en suma que estaría todavía privado de todas las dimensiones antropológicas, teológicas, y políticas, por consiguiente ónticas y ontológicas, de la soberanía. ${ }^{26}$

Lo apunta así desde un fragmento del Die ontotheologische Verfassung del Metaphysik (1957) -que renombra Die-onto-theo-logische Verfassung der Metaphysikporque aquello que Heidegger pretende aprovechar en Walten -continúa Derrida- intima algo "tan soberano, ultra-soberano que desborda toda configuración histórica de tipo ontoteológico y por tanto también teológico-político"27

E inmediatamente, sólo tras bosquejos filológicos y registros semánticos en 'lo que domina por la fuerza, la violencia, el poder', reenvía a una cita de Heidegger en el Curso de Friburgo, semestre de invierno 1929-1930, guardada en Einführung in der Metaphysik (1935): ${ }^{28}$

Reina (waltet) una superioridad esencial del espíritu en relación con todo lo que es puramente ciencia" (eine wesenhafte Überlegenheit des Geistes gegenüber aller blossßen Wissenschaft waltet). La soberanía del espítitu -Walten- que se impone, prevalece, se afirma por encima de la ciencia, de toda mera ciencia. ${ }^{29}$

\footnotetext{
${ }^{26}$ DERRIDA, Jacques. Seminario La bestia y el soberano, trad. de Luis Ferrero, Cristina de Peretti y Delmiro Rocha, Buenos Aires: Manantial, 2011, p.315-349, en esp. p. 337.

27 DERRIDA, Jacques. Seminario La bestia y el soberano, trad. de Luis Ferrero, Cristina de Peretti y Delmiro Rocha, Buenos Aires: Manantial, 2011, p.315-349, en esp. p. 337.

${ }^{28}$ HEIDEGGER, Marti. Los conceptos fundamentales de la metafísica. Mundo- Finitud-Soledad, trad. de Joaquín Alberto Ciria Cosculluela, Friedrich-Wilhelm von Herrmann ed., Madrid: Alianza Editorial, 2007, p. 67. Véase asimismo VON HERRMANN, Friedrich-Wilhelm. Subjekt und Dasein.Interpretationen su ,Sein und Zeit. Frankfurt am Mains: Klostermann, 1974, p. 80-81.

${ }^{29}$ DERRIDA, Jacques. Seminario La bestia y el soberano, trad. de Luis Ferrero, Cristina de Peretti y Delmiro Rocha, Buenos Aires: Manantial, 2011, p. 340.
} 


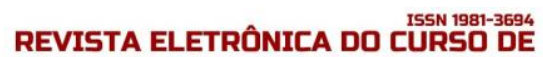

\section{REFERÊNCIAS}

ATIENZA, Manuel. El sentido del Derecho. Barcelona: Editorial Ariel, 2001.

BAKER, Gordon .P. ; HACKER, Peter M.S. Language, sense and nonsense: a critical investigation into modern theories of language. Oxford: Blackwell, 1984.

BARTHES, Roland. Literatura y significación. In: BARTHES, Roland. Ensayos críticos, trad. de Carlos Pujol, Barcelona: Seix Barral, 1967.

BARTHES, Roland. Una problemática del sentido. (1970). In: BARTHES, Roland. Variaciones sobre la escritura, selec. y trad. de Enrique Folch González, Barcelona: Paidós, 2002.

BATAILLE, Georges. Lo que entiendo por soberanía (1953), trad. de Pilar Sánchez Orozco y Antonio Campillo, introd. de Antonio Campillo, Barcelona: Paidós/I.C.E. de la Universidad Autónoma de Barcelona, 1996.

BLANCHOT, Maurice. L'espace littéraire, trad. de Vicky Palant y Jorge Jinkis e introd. de Anna Poca, Buenos Aires: Paidós, 1969.

BLANCHOT, Maurice. Aminadab. Paris: Le Très-Haut, Gallimard, 1949.

BOBBIO, Norberto. Le bon législateur. In: BOBBIO, Norberto. Le raisonnement juridique. Bruxelles: Ed. Hubert Hubien, Etablissement Émile Bruylant, 1971.

BOCKENFORDE, Ernst. Escritos sobre derechos fundamentales, trad.de Juan Luis Requejo Pagés e Ignacio Villaverde Menéndez, Baden-Baden: Nomos Verlarsgesellchaft, 1993.

CALVOGONZALES, José. De la nostalgia civil: la soberanía popular. In: PALOMBELLA, Gianluigi. Constitución y soberania: El sentido de la democracia constitucional. Granada: Editorial Comares, 2000.

CALVOGONZALES, José. Direito curvo, trad. de André Karam Trindade, Luis Rosenfield y Dino del Pino, Posfácio de Lenio Luiz Streck, Porto Alegre: Livraria do Advogado, 2013.

CARCOVA, Carlos María. Las teorías jurídicas post positivistas. Buenos Aires: Lexis Nexos, 2007 [ $2^{\mathrm{a}}$ ed. en Abeledo Perrot, Buenos Aires, 2009].

CARPENTIER, Alejo. Viaje a la semilla (1944). In: CARPENTIER, Alejo. Guerra del tiempo y otros relatos. Madrid: Alianza Editorial, 1958.

DELEUZE, Gilles. Lógica del sentido, trad. de Víctor Molina y Miguel Morey, pról. de Miguel Morey, Barcelona; Buenos Aires; México: Paidós, 1989.

DERRIDA, Jacques. Seminario La bestia y el soberano, trad. de Luis Ferrero, Cristina de Peretti y Delmiro Rocha, Buenos Aires: Manantial, 2011. 


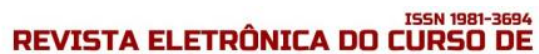

JosÉ CALVOGONZÁLEZ

EZQUIAGA GANUZAS, Francisco Javier. La argumentación en la justicia constitucional española. Oñati: Instituto Vasco de Administración Pública, 1987.

FORSTHOFF, Ernst. Rechtsstaat im Wandel, Verfassungrechtliche Anhandlungen. Stuttgart: W. Kohlhammer Verlag, 1964.

FOUCALT, Michel. La pensée du dehors. Critique, ed. 229.

GUASTINI, Ricardo. Estudios sobre la interpretación jurídica, trad. de Marina Gascón y Miguel Carbonell, México: Instituto de Investigaciones Jurídicas, Editorial Porrúa/UNAM, 2000.

HEIDEGGER, Marti. Los conceptos fundamentales de la metafísica. Mundo- Finitud- Soledad, trad. de Joaquín Alberto Ciria Cosculluela, Friedrich-Wilhelm von Herrmann ed., Madrid: Alianza Editorial, 2007.

ISONOMÍA. Argumentos interpretativos y postulado del legislador racional. Revista de Teoría y Filosofía del derecho, ed. 1, 1994.

KANDINSKY, Wasily. De lo espiritual en el arte y la pintura en particular, trad. de Edgar Bayley, Buenos Aires: Galatea Nueva Visión, 1971.

KELSEN, Hans. La Teoría Pura del Derecho: Introducción a la Problemática Científica del Derecho, con pról. de C. Cossio, Editora Nacional México: Editora Nacional, 1981.

LÁZARO, Manuel Arranz. El pensamiento del afuera. Valencia: Pre-textos, 2008.

OST, François, L'interprétation logique et systématique et le postulat de rationalité du législateur. L'interpretation en droit : Approche pluridisciplinaire, Publications des Facultés Universitaires Saint-Louis, Bruxelles: Ed. Michel van de Kerchove, 1978.

PAZ, Juan Carlos, Arnold Schoenberg, o el Fin de la era tonal. Buenos Aires: Editorial Nueva Visión, 1958.

SCHOENBERG, Arnold. Fundamentals of Music Composition (1967), trad. de A. Santos, Madrid: Grupo Real Musical, Villaviciosa de Odón, 2000.

SCWARTS, Richard D.; MILLAR, James C. Legal Evolution and Societal Complexity. American Journal of Society, ed. 70, 2, 1964.

TARELLO, Giovanni. L'interpretazione della legge. Milano: Giuffrè, 1989.

VON HERRMANN, Friedrich-Wilhelm. Subjekt und Dasein.Interpretationen su ,Sein und Zeit. Frankfurt am Mains: Klostermann, 1974.

\section{ARTIGO CONVIDADO}

